\title{
A Study on the Influence of PBL Class on Mathematics Learning Interest ${ }^{1}$
}

\author{
Lee JoongKwoen \\ Professor \\ Dongguk University \\ South-Korea \\ E-mail: joonglee@ dgu.ac.kr
}

\begin{abstract}
The purpose of this study was to find out the effect of a group discussion PBL (Problem Based Learning) class on math learning interests. The results of the analysis on the research problem are as follows. There were significant differences in interest in mathematics among the experimental class students who took the PBL group discussion class and in the general class in mathematics. The PBL group discussion class was found to have worked to positively change students' interest in math. Through the PBL group discussion class, students have become more confident in solving math problems. Therefore, it can be concluded that PBL group discussion classes improve students' interest in learning math.
\end{abstract}

Index Words: PBL Collective Discussion Class, Math Study Interest, Math Problem Solving

\section{Introduction}

Ministry of Education, Science and Technology (2015), Department of Mathematics and Curriculum, Ministry of Education, Science and Technology (MOE) addressed the six key competences in mathematics. One of them is the proposed solution of mathematical problems. The revised math and curriculum 2015 (Ministry of Education, Science and Technology, 2015) specifies the following matters concerning problem solving. The purpose of the problem is to discover what is obtained through the understanding process of the problem and to identify the conditions and to clarify the problem, analyze the problem and correctly recognize the problem by analyzing the given things, conditions, relationships, and goals, analyze whether important mathematical principles or results are available through the problem solving strategy search process, and use various appropriate strategies for problem solving so that the solution can develop a solution plan by exploring appropriate findings(Choi Jeong-im\& Chang Kyung-won, 2015). We also valued the ability to perform collective problem solving through group interaction and balanced accountability.

Thus, in line with the emphasis made in the 2015 revised math and curriculum in Korea, the effects of a PBL (Problem Based Learning) group discussion class (Roberts \&Stylianides, 2012) on interest in learning mathematics were studied. This study conducted a study on the effects of PBL group discussion classes on mathematics learning interest, focusing on the triangular ratio unit of middle school students.

\section{Research problem}

In this study, the purpose of the study is to test the effectiveness of PBL group discussion teaching and learning by analyzing students' interest in learning mathematics after applying PBL group discussion teaching and learning based on the triangular ratio unit of middle school students to analyze the effects of PBL group discussion teaching and learning in the 2015 revision of mathematics and education courses. To achieve this objective, the following research issues were established: Does PBL Collective Discussion teaching/Learning have a significant effect on learners' interest in mathematics learning?

\section{Research design}

Through prior study, 34 students in Class A applied to general instructor-led math classes were selected out of 10 classes in K middle school in S City, and 35 students in Class B applied with PBL group teaching and learning were selected as the experimental group. In this study, to find out the impact of math classes using PBL group discussion professors and learning on students' interest in mathematics, the experimental group used PBL group teaching and learning to conduct classes and the control group conducted general lecture sessions (Schuller, 2005). I used Aiken's Math Interest Checklist to find out how interesting math is. 35 students in class B made seven groups of five.

\footnotetext{
${ }^{1}$ This Research Supported by Dongguk University
} 
The PBL group discussion teaching and learning models used in the experimental study (Leahy, M., \&Walshe, I, 2005) are as follows: The PBL Collective Discussion teaching/Learning (Savery, 2006) was conducted in the development of [Figure 1] PBL Collective Discussion Model as follows:

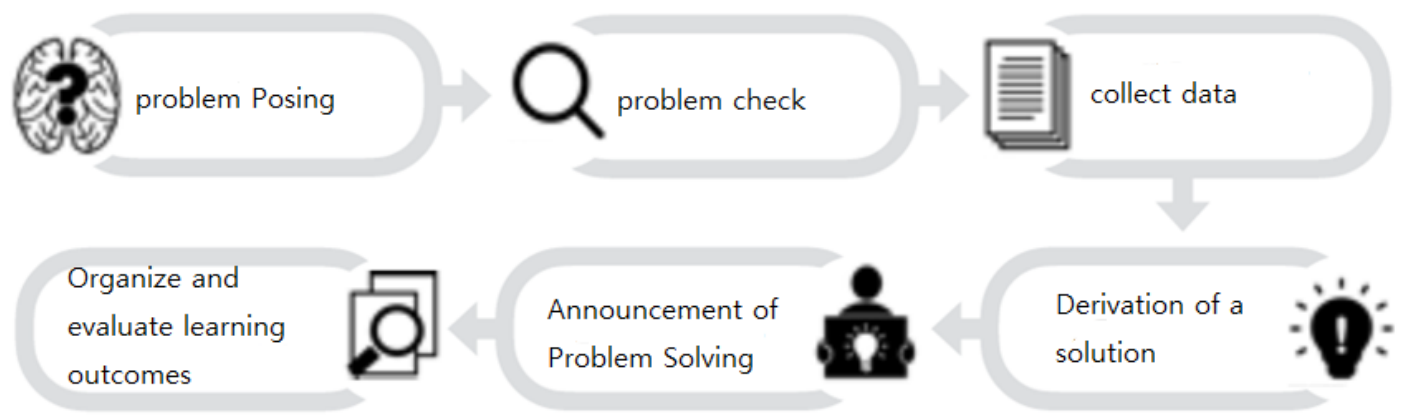

[Figure 1] PBL Collective Discussion Model

\section{1) Problem posing}

The first phase of the PBL presented issues that needed to be addressed (Donner, \&Bickley, 1993). The professor prepared and presented the questions to the learners in class in advance. Issues in the PBL are presented in various forms. In understanding the problem, the learners learned what to learn (Allen, D., \& Tanner, K, 2003) and encouraged the students to feel responsible for their learning activities. The math problem presented the possible problem of the making mathematics of Freudenthal (Kim Yeon-sik, Jung Young-ok, 2003), which can be experienced in real life. It also provided guidance on the types of tasks that should be submitted finally when presenting problems.

2) Problem check

When the problem is presented, the learner has given enough time to identify what problem needs to be solved and to think about how to find a solution. In the problem identification phase, the learners were asked to identify the problem in groups and examine the problem in detail to find out what the solution required by the problem is. In order to solve the problem, learners were advised to examine the problem through the steps of 'thought', 'facts', 'learning tasks' and 'practice planning'.

\section{3) Collect data}

When the group activities for problem identification are completed, data and information for problem resolution are collected. This data collection was induced so that each of the group members could be conducted as an individual study that addresses the learning tasks given to them (Barrows, 1985). Through this course, learners were able to develop self-directed learning ability to find and learn information using a variety of self-directed resources.

4) Derivation of a solution

At this stage, a reassessment of the problem was conducted based on the identified data at the problem presentation stage. After individual learning, the learners gathered again in groups to present the results of each individual's study and to collect opinions to coordinate identified thoughts, facts, learning tasks and future tasks. The optimal solution was to be derived through the process of reassessing the problem based on the identified data. If the final solution was not reached in this process, the problem re-examination process could be repeated until the final solution was reached.

\section{5) Announcement of problem solving}

When the final problem solution was created by each group through the problem re-confirmation step, each group presented the problem solution prepared by each group in class. At this stage, the process of comparing ideas from other groups with those from his team encouraged him to experience the experience of encountering and reflecting on best practices. Finally, the most desirable solution was to be sought through a full discussion.

6) Organize and evaluate learning outcomes

The final step was to summarize the PBL learning results and to evaluate the results and performance of the learning the learner compiled the solution through the presentation of the results. Teacher summarized, organized, or provided a brief lecture on the main concepts associated with the problem solution. The assessment of the learning outcomes used the teacher's assessment of the problem solutions presented by each group, self-assessment of the learners (Borrego, Rhyne, Hansbarger, Geller, Edwards, Griffin, McClain, \& Scaletti, 2000). 


\section{Research Method}

Quantitative research methods were used as research methods. Prior study was conducted prior to the commencement of this study. The preliminary study was conducted to confirm the homogeneity of math interests of the second class of $\mathrm{K}$ middle school seniors. As a result of the pre-measurement, two classes before the PBL group discussion class showed no significant difference in math interest, so they were judged as homogenous groups of math interest. The two classes were divided into one control group of experimental groups that conducted PBL-collective discussion and general classes. After conducting the experimental class, Aiken's mathematical interest test data were used to analyze statistical significance.

$<$ Table II-1> Research Design

\begin{tabular}{|l|l|l|l|}
\hline Group & Pre-test & Experimental treatment & Post-test \\
\hline $\begin{array}{l}\text { Control group- } \\
\text { A }\end{array}$ & • Aiken Math & $\begin{array}{l}\text { PBL Collective Discussion } \\
\text { Teaching/Learning Class }\end{array}$ & • Aiken Math \\
\cline { 1 - 1 } $\begin{array}{l}\text { Experiment } \\
\text { group-B indy interest test }\end{array}$ & study test & General lecture course & \\
\hline
\end{tabular}

As shown in <Table II-1> in this study, t-test was performed using Aiken's Mathematical Interest Test Sheet to examine the homogeneity of the two groups. In post-examination, Aiken's mathematics interest test paper was used to analyze the changes in interest in mathematics learning in both groups before and after the experiment. The analysis used the statistical program SPSS. Before the experimental class, the homogeneity of the experimental group and the control group was verified by conducting independent specimen t-test among the analysis tools of the SPSS. The corresponding sample t-test was performed for analyzing the results of the pre- and post-inspection of each group to check the differences. The significance level $\alpha$ in $<$ Table II-2> is set at 0.05.

$<$ Table II-2> Test Tool

\begin{tabular}{|l|l|l|l|}
\hline \multirow{2}{*}{ Test item } & Test tool & \multirow{2}{*}{ Result test } \\
\cline { 3 - 5 } $\begin{array}{l}\text { Math study } \\
\text { interest }\end{array}$ & $\begin{array}{l}\text { Aiken's Math Study Interest } \\
\text { Checklist }\end{array}$ & $\begin{array}{l}\text { Aiken's Math Study } \\
\text { Interest Checklist }\end{array}$ & t-test \\
\hline
\end{tabular}

\section{Math Study Interest Test}

1) Pre- interest, and homogeneity test

The pre- interest test was conducted to ensure that the control group and the experimental group had the same interest in mathematics learning before the experiment. Math study interest test was performed once each time before and after using Aiken's math study interest test paper to examine the examiner's paper consists of 11 questions that show interest in math subjects. The test scale for each question is as shown in 〈Table II-3〉 and the score for the negative question is calculated as minus ('-'). Therefore, if the result of the examination was scored high, it was interpreted as having good interest in learning math.

$<$ Table II-3> Aiken's scale of interest in mathematics

\begin{tabular}{|l|l|l|l|l|l|}
\hline Contents & very much so & so much & normal & no & not at all \\
\hline point & 5 & 4 & 3 & 2 & 1 \\
\hline positive question & $1,2,4,6,7,9,11$ \\
\hline negative question & $3,5,8,10$ & \\
\hline
\end{tabular}

2) Collective homogeneity test results and analyses of interest in mathematics learning

A homogeneity t-test was conducted based on pre-Aiken's math learning interest test data to verify homogeneity of interest in mathematics learning between the control and the experimental group. Math learning interest, homogeneity, t-test hypothesis settings are as follows.

Null hypothesis: there is a difference in interest in mathematics learning between pre-controlled and experimental groups $\left(\mu 1 \neq \mu^{r}\right)$.

Alternative hypothesis: There is no difference in the interest of mathematics learning by pre-controlled and experimental groups $\left(\mu 1=\mu^{r}\right)$. 
<Tables II-4> Pre-math learning interest homogeneity t-test results

\begin{tabular}{|l|l|l|l|l|l|}
\hline & $\mathrm{N}$ & Average & SD & $\mathrm{t}$ & $\mathrm{p}$ \\
\hline Control group & 34 & 69.88 & 3.2658 & \multirow{2}{*}{0.0427} & \multirow{2}{*}{0.0356} \\
\hline Experiment group & 35 & 68.07 & 3.9540 & & \\
\hline
\end{tabular}

In Table II-4 the pre-test of math learning interest and homogeneity for the two groups set at a significant level $p=0.0356$ shows that the two groups are homogenous because they are less than $\alpha=0.05$, rejecting the null hypothesis and accepting arguments of confrontation.

3) Post-test of math learning interest

The post-diplomatic learning interest test is designed to identify the variation in interest in mathematics learning between the control group and the experimental group after conducting the experiment. The post-diplomatic learning interest test paper used the same Aiken's math learning interest test paper that was used for the pre-math learning interest test. The class for research was set up as a research unit for the third grade math textbook triangle ratio and the class was conducted using the PBL group discussion teaching/learning model.

\section{Research problem analysis results}

To check the effect of learning math on students' interest in learning by using PBL group discussion teaching and learning, Aiken's math study interest test sheet data were used. Pre- and post- math study interest data of the experimental group and the control group that applied mathematics learning using PBL group discussion teaching and learning and conducted general lecture classes were analyzed by t-test.

\section{Control group}

The t-test hypothesis settings for math learning interest in the control group are as follows.

Null hypothesis: There is a difference in interest in mathematics learning in the group of pre- and post-controls ( $\left.\mu 1 \neq \mu^{r}\right)$.

Alternative hypothesis: There is no difference in interest in mathematics learning in the group of pre- and post-controls $(\mu 1=\mu r)$.

$<$ Table III-1>Control group mathematics learning change t-test result

\begin{tabular}{|l|l|l|l|l|l|l|}
\hline \multicolumn{2}{|l|}{} & $\mathrm{N}$ & Average & SD & t & $\mathrm{p}$ \\
\hline $\begin{array}{l}\text { Control } \\
\text { group }\end{array}$ & pre & 34 & 69.88 & 3.2658 & \multirow{2}{*}{0.0532} & 0.0407 \\
\cline { 2 - 6 } & post & 34 & 73.54 & 3.8694 & & \\
\hline
\end{tabular}

In Table III-1, the control group's students averaged from 69.88 to 73.54 points before class, an average improvement of 3.65 points. As a result of the corresponding t-test, it can be said that the t-value is 0.0532 , the significant probability of $p=0.0407$ at the significant level $\alpha=0.05$, and that there is no difference in the interest of the post-control group in mathematics compared to the opposing theory.The t-test hypothesis settings for interest in learning mathematics in experimental groups are as follows.Null hypothesis: There is no difference in interest in mathematics learning by postexperimental groups $\left(\mu 1=\mu_{c}^{r}\right.$ ). Alternative hypothesis: There is a difference in interest in mathematics learning by postexperimental groups $\left(\mu 1 \leq \mu^{r}\right)$.

$<$ Table III-2> Changes of Interest in T-Test Results

\begin{tabular}{|l|l|l|l|l|l|l|}
\hline \multicolumn{2}{|c|}{} & $\mathrm{N}$ & Average & SD & t & p \\
\hline \multirow{2}{*}{ Experiment group } & pre & 35 & 68.07 & 3.9540 & \multirow{2}{*}{0.0202} & \multirow{2}{*}{0.0161} \\
\cline { 2 - 6 } & post & 35 & 77.40 & 3.5814 & & \\
\hline
\end{tabular}

In Table III-2 the students in the experimental group improved 9.32 points on average from 68.07 points to 77.40 points before taking the class, and the corresponding t-test results showed that the t-value of 0.0202 and significant probability of $p=0.0165$ were rejected $(\alpha=0.05)$ and the mathematics learning level of the antagonistic post-experimental group improved As shown above, it can be said that mathematics learning, which utilizes PBL group discussion teaching and learning in the study of triangle ratio, a third grader in middle school, has a positive effect on students' interest in learning math.

\section{Conclusion}


To understand mathematics, it is necessary to put knowledge into the context of the original discovery, or in the context that humans intend to use (Haven, 2000; Egan, 2005; Zazkis\&Liljedahl, 2008).

It is also important that students get high scores by solving problems in math class, but it is also important for students to participate in the class with interest without being rejected by math. After taking a class using PBL-studied discussion teaching and learning of trigonometric ratio, the experimental group that conducted math teaching using PBL discussion teaching and learning had a significant difference in their interest in mathematics learning compared to the control group. On the subject of this study, the following conclusions were reached:

First, students in a control group who have been lectured on the concept of trigonometric ratios can say that the interest in mathematics has not improved significantly, and that the interest in learning mathematics is not much different from the pre- and post-examination.

Second, both the control group and the experimental group have improved their interest in mathematics learning, but the experimental group that used PBL group discussion teaching and learning to learn the concept of trigonometry has improved more significantly than the students of the control group who have guided them to the general instructor-led class. Therefore, it can be seen that classes using PBL group discussion teaching and learning have been effective in improving interest in mathematics learning.

Third, the PBL group discussion students who took part in math learning preferred math to those who took part in regular class. At first, there were many students who were unfamiliar with the class using PBL group students who were struggling with long sentences, but as they progressed, most of them began to enjoy themselves. By solving various problems, there was confidence in being able to solve other problems as well, and there was less resistance to math. Therefore, it can be seen that students' interest in learning math has improved. The subject of mathematics is difficult to solve because only the formula is memorized(Strobel, \& Van Barneld, 2009). However, teachers should be able to utilize various problems and help students understand them with stories. Classes using PBL group discussion teaching and learning can have positive results in their interest in math learning by helping students feel interested in math and actively participate in the class.

\section{References}

Allen, D., \& Tanner, K. (2003). Approaches to Cell Biology Teaching: Learning Content in Context—Problem-Based Learning, Cell Biology Education, 2, 73-81.

Barrows, H. S. (1985). How to design a problem-based curriculum for the preclinical years. New York: Springer.

Barrows, H. S. (1988). The tutorial process (3th edition). SeoJeong-don, AhnByung-hun, and Son Hee-jung. (2005). Dr. Howard Barlows' Tutorial. Seoul: Sungkyunkwan University Press.

Barrows, H. S. (1994). Practice-Based learning: Problem-based learning applied tomedical education. Springfield, IL: Southern Illinois University School of Medicine.

Borrego, M. E., Rhyne, R., Hansbarger, L. C., Geller, Z., Edwards, P., Griffin, B.,McClain, L., \&Scaletti, J. V. (2000). Pharmacy Student Participation in Rural

Interdisciplinary Education Using Problem Based Learning (PBL) Case Tutorials,American Journal of Pharmaceutical Education, 64, 355-363.

Choi Jeong-im and Jang Kyung-won (2015). To teach by PBL. Seoul: the dean of the academic department.

Donner, R. S., \&Bickley, H. (1993). Problem-based learning in American medicaleducation: an overview, Bull Med LibrAssoc, 81(3), 294-298.

Egan, K.(2005). An imaginative approach to teaching. Eurasia Journal of Mathematics, Science \& Technology Education, 2007, 3(3), pp.247-248.

Haven, K.(2000). Super simple storytelling: A can-do guide for every classroom, every day. Englewood, CO: Teacher Ideas Press.

Jang Kyung-won (2015). A Study on Teams-Based Individual Problem Solving Learning for University Classes. Among learners a deep-textured study 15(4), 255-284.

Kim Yeon-sik and Jung Young-ok (2003). Freudenthal's study of mathematicalization--the study of cartography. Woo Woo-ho, 2004 I, a professor of mathematics and education an epigraphist.

Leahy, M., \&Walshe, I. (2005). Designing a Problem-Based Learning(PBL) Module: A Case Study of a Speech and Language Therapy Module at Trinity College Dublin, Handbook of Enquiry \& Problem Based Learning, Barrett, T., Mac Labhrainn, I., Fallon, H. (Eds). Galway: CELT, 2005.

Ministry of Education, Science and Technology (2015). ० Mathematics and curriculum according to the revised 2015 curriculum Ministry of Education, Science and Technology 
Rich, S. K., Keim, R. G., Shuler, C. F. (2005). Problem-Based Learning versus a Traditional Educational Methodology: A Comparison of Preclinical and Clinical Periodontics Performance, Journal of Dental Education, 69(6), 649662.

Roberts \&Stylianides. (2012), Telling and illustrating stories of parity: a classroom-based design experiment on young children's use of narrative in mathematics.

Savery, J. R. (2006). Overview of Problem-based Learning: Definitions and Distinctions. Interdisciplinary Journal of Problem-Based Learning, 1(1).

Strobel, J., \& van Barneveld, A. (2009). When is PBL More Effective? A Meta-synthesis of Meta-analyses Comparing PBL to Conventional Classrooms. Interdisciplinary Journal of Problem-Based Learning, 3(1).

<Appendix 1> Aiken's test of interest in mathematics

Name: Grade:

I am going to investigate the thoughts and attitudes that I feel when I study math.

Please, answer each question honestly.

\begin{tabular}{|l|l|l|l|l|l|l|}
\hline & Survey content & $\begin{array}{l}\text { very much } \\
\text { so }\end{array}$ & $\begin{array}{l}\text { so } \\
\text { much }\end{array}$ & normal & no & $\begin{array}{l}\text { not at } \\
\text { all }\end{array}$ \\
\hline 2 & $\begin{array}{l}\text { I enjoy solving new math problems as } \\
\text { mell as solving new math problems that } \\
\text { my teacher gave me. }\end{array}$ & & & & \\
\hline 3 & $\begin{array}{l}\text { Math gives me pleasure and motivation. } \\
\text { embarrassed. }\end{array}$ & & & & & \\
\hline 4 & $\begin{array}{l}\text { I try to use the knowledge of } \\
\text { mathematics I learned at school in } \\
\text { everyday life. }\end{array}$ & & & & & \\
\hline 5 & Math is a subject that I hate. & & & & \\
\hline 6 & $\begin{array}{l}\text { I always enjoy studying math at school. } \\
\text { I study a lot to build up my math skills. }\end{array}$ & & & & & \\
\hline 7 & Math makes me nervous. & & & & \\
\hline 8 & $\begin{array}{l}\text { I am trying to acquire a good knowledge } \\
\text { of mathematics. }\end{array}$ & & & & & \\
\hline 10 & $\begin{array}{l}\text { Math is boring because I can't give a } \\
\text { personal opinion. }\end{array}$ & & & & & \\
\hline 11 & Math is fun, so I always do my best. & & & & & \\
\hline
\end{tabular}

